\title{
Breaking the Tyranny of the Semester: A Phase-Gate Sprint Approach to Teaching Colorado School of Mines Students Important Engineering Concepts, Delivering Useful Solutions to Communities, and Working on Long Time Scale Projects
}

\author{
Jered H. Dean \\ Teaching Associate Professor \\ Department of Mechanical Engineering \\ Colorado School of Mines \\ jdean@mines.edu
}

\author{
Douglas L. Van Bossuyt ${ }^{1}$ \\ Assistant Professor \\ Department of Mechanical Engineering \\ Colorado School of Mines \\ dvanboss@mines.edu
}

Abstract - The Colorado School of Mines (CSM) hosts the oldest Humanitarian Engineering (HE) minor program in the USA, originally started in 2004. During the 2012/2013 academic year the program was overhauled and new curriculum was introduced. Several deficiencies in senior capstone courses were noted including poor quality of designs resulting from the tyranny of the rigid semester schedule; students focusing on the technical aspects of a design project while largely ignoring the social, financial, and sustainable aspects; and a loss of knowledge between academic terms due to turnover of students. These were addressed in the development of the Projects for People course through several methods. The course has been offered for two semesters and will be offered in multiple sections in the immediate future. Students, CSM faculty, and NGO partners have all found the course to be useful and rigorous, and the HE faculty have found the resulting designs to be of high quality.

Index Terms - Humanitarian Engineering, Engineering by Doing, Project Based Learning, Design Education

\section{INTRODUCTION}

A recent revision of the Humanitarian Engineering (HE) minor curriculum at the Colorado School of Mines (CSM) created an opportunity for the introduction of a new project-based learning (PBL) course. The HE minor originally was developed and implemented in the 2004/2005 academic year, and featured a senior capstone project that was semester-based and required students to produce a final project by the end of the second semester regardless of the potential for success of the project. The HE capstone project course was taught combined with the general student senior capstone project course but required students to complete a $\mathrm{HE}$ project. A central issue with HE projects in the past at CSM was poor designs. Due to the rigid requirements of a senior capstone course and the semester schedule, students were forced to produce a design that often was not "good" and hurt the community or customer more than helped. Projects that were not complete or had not produced a "good" design were very difficult to restart the next senior capstone course cycle with significant knowledge being lost when

\footnotetext{
${ }^{1}$ Corresponding Author
} 
turnover in the students working on the project occurred. Students were also focusing primarily on technical aspects of the $\mathrm{HE}$ projects to the detriment of social, financial, and sustainable aspects.

The HE faculty developed a new PBL course, Projects for People, to address several shortcomings in existing HE PBL courses such as the senior design capstone sequence. The Projects for People course implemented a phase gate and sprint approach to project management that ensures "good" designs make it to customers and communities; a robust knowledge transfer system to ensure knowledge about a project is retained between semesters and through student turnover; and required significant work products from students focused individually on social, financial, sustainable, and technical aspects of the projects. The course has been taught for two semesters and has seen success both in delivering "good" design results, and in educating students on several topics including holistic design approaches that balance technical and nontechnical aspects of design, customer and community-focused design solutions, the phase gate and sprint approach to project management. In coming semesters, the course will be expanded to offer multiple sections. Several pedagogy methods piloted in the Projects for People course are now being implemented into other design classes in the CSM curriculum.

\section{BACKGROUND}

CSM offers a HE minor that is available campus-wide. The HE minor was originally offered to students starting in the 2004/2005 academic year and was the first such program offered in the USA. Now many HE and engineering service learning programs exist at American universities ${ }^{1}$. During the 2012/2013 academic year, a significant revision and update to the HE curriculum was made. This provided a unique opportunity for curricular experimentation.

Coinciding with the HE curriculum redesign, but unrelated, several faculty brainstorming sessions were held on campus focusing on how to add more Engineering by Doing (EbD) ${ }^{2,3}$ into the curriculum. It was decided that $\mathrm{EbD}$, featuring socially-relevant projects requiring engineering problem solving, and social as well as technical complexity, in line with the National Academy of Engineering's definition of "design under constraints", should be implemented into the curriculum. While this call for socially-relevant projects can be tied to broader needs in higher education ${ }^{5}$, it served to further highlight the importance of the HE program at Mines.

The faculty group in charge of the HE curriculum redesign had special interest in projects that would be able to go through an entire project lifecycle to a meaningful conclusion. There was great concern among the faculty of avoiding "projects for projects sake." Additionally, the faculty stated that EbD projects must uphold the principles of equity and sustainability as vital to, and integrated with, the success of engineering. Thus, the faculty embarked upon developing a new course for the HE curriculum titled Projects for People.

Properly addressing Humanitarian Engineering challenges requires students to deeply engage with the nontechnical aspects of design. The decision to integrate EbD into the HE curriculum allowed for development of a direct education intervention strategy. Engineering students have been historically taught to solve technical, tightly defined problems ${ }^{6}$. Integrating Ebd into the HE program presented an ideal opportunity to introduce students to more holistic design approaches that focus both on the technical and the nontechnical aspects of design.

At CSM, a significant problem for HE design projects within the traditional curriculum of the senior capstone design courses has been identified. The semester system and demands of the senior capstone design courses force students to develop solutions that often poorly address the 
needs of HE project customers. There is a great danger that solutions are designed to fit the semester schedule rather than the actual need. Successful programs at other universities such as Purdue's EPICS program have broken from traditional capstone frameworks in part to address issues of poor designs being provided to communities ${ }^{7,8}$. The primary challenges presented by the capstone program included:

- Requiring students to proceed from concept to prototype in one or two semesters,

- Encouraging students to focus on the application of technical undergraduate coursework to the exclusion of other important design considerations, and

- A complete turnover in students working on the project every year resulting in significant project knowledge loss, especially on projects that span over multiple academic years.

These issues create significant challenges for $\mathrm{HE}$ projects to successfully operate within senior capstone courses. Poor design results on any capstone project can damage customer/community trust in the program. However, for HE projects poor results can leave communities in a worse position than they were prior to the student project ${ }^{9,10}$. Said more succinctly, no engineering intervention is often more advantageous than a poor HE engineering intervention.

\section{Design of the Projects for People Course}

The goal in designing the Projects for People course was to develop a course that had the option to "produce no engineering intervention" if that was the correct answer. Design of the Projects for People course started with the following high-level requirements:

- Build the course around EbD projects where students are able to apply knowledge to realworld projects

- Integrate a holistic design approach that explicitly balances the technical and nontechnical aspects of design

- Accept that projects can be multi-term, multi-team and include strong frameworks to ensure continuity

- Solutions should not be released to customers/communities until the solutions have matured into a "good design"

The requirements were addressed in several ways including: 1) partnering with NGOs to serve as intermediaries with communities ${ }^{11}, 2$ ) clearly defining what a "good design" is and fostering the expectation that student-created designs will be "good designs" before being released, 3) developing a teaching and assessment framework that focuses on social, technical, financial, and sustainable design, 4) implementing a flexible structure that allows for short projects, semester-length projects, multi-semester projects, and multi-year projects, and 5) implementing a phase-gate and sprint approach to design. Each of these items is detailed below. 


\section{NGO PARTNERING}

Projects for the new course are only accepted from NGOs acting as intermediaries for communities. While this may seem controversial, good NGO partners help students and faculty avoid common pitfalls of educational mission trips which often involve providing technical solutions in an attempt to "help"12,13. Quality NGO's longstanding community relationships can help guide students and faculty to appropriate solutions ${ }^{14}$. In addition, good NGO partners ensure that student work has legitimacy, accountability at multiple levels, and provides stronger opportunities for long-term assessment of impacts ${ }^{11}$. This approach is in line with UNESCO recommendations ${ }^{15}$, and is practiced by groups such as Engineers Without Borders USA ${ }^{16}$ and others. The NGOs that the CSM HE program routinely works with have shown great interest in the approach taken by the Projects for People course and have been valuable in helping us craft and improve the course.

\section{“GOOD DESIGN” DEFINITION}

The Humanitarian Engineering Minor program at Mines requires students to complete equal parts design and liberal arts courses ${ }^{17}$. This choice to balance the credit hours was intentional and explicit by the HE curriculum development team. However, the balance is often lost when students begin work on a design problem. How to apply the "non-technical" coursework in a "technical" setting is a major cognitive challenge for most CSM HE students.

Human Centered Design (HCD) methods are a commonly used tool for addressing the "nontechnical" side of design ${ }^{18}$. By focusing on empathy and user engagement at the beginning of a project, and prototyping/testing as the project progresses, HCD can be a powerful teaching tool. For those reasons, the HCD Toolkit ${ }^{18}$ co-developed by IDEO and iDE was chosen as one of the two required texts for the course. Students are expected to read and apply the HCD process and particular class activities are taken directly from the HCD Toolkit.

However, proper application of HCD requires an ongoing mindful, reflective process ${ }^{19}$ and many CSM HE students have shown a tendency to turn off HCD principles once the "real engineering" begins. For the purposes of the Projects for People course another major concern is that HCD, as defined in the HCD Toolkit, only looks for desirability (user/stakeholders), viability (financial) and feasibility (technical). Sustainability, specifically as defined by Lucena, Schneider, and Leydens ${ }^{20}$, is not explicitly addressed. While it can be argued that proper consideration of the desirability area would address this definition of sustainability, in practice that level of integrative thinking was not happening in the classroom.

For these reasons, a custom definition of "good design" was developed. The definition is closely aligned with the "three lenses" as defined in HCD but highlights the importance of social/environmental concerns ${ }^{18}$. On the first day of class students in Projects for People are presented with the HCD Toolkit book and the NCEES FE Reference Handbook ${ }^{21}$ and told, "you are going to learn how to balance these things." The definition given to the students of good design is a solution that balances social, technical, and sustainability within the market. The concept is illustrated with the diagram shown in FIGURE 1. This definition is reinforced through real-world examples including past CSM HE projects that have both been "good designs" and "bad designs." In addition, it is important to note that students in the HE minor program will have taken a course on Engineering and Sustainable Community Development (ESCD) ${ }^{20}$ at this 
point which, through the use of multiple case studies, explores the downfall of techno-centric engineering interventions in the past.

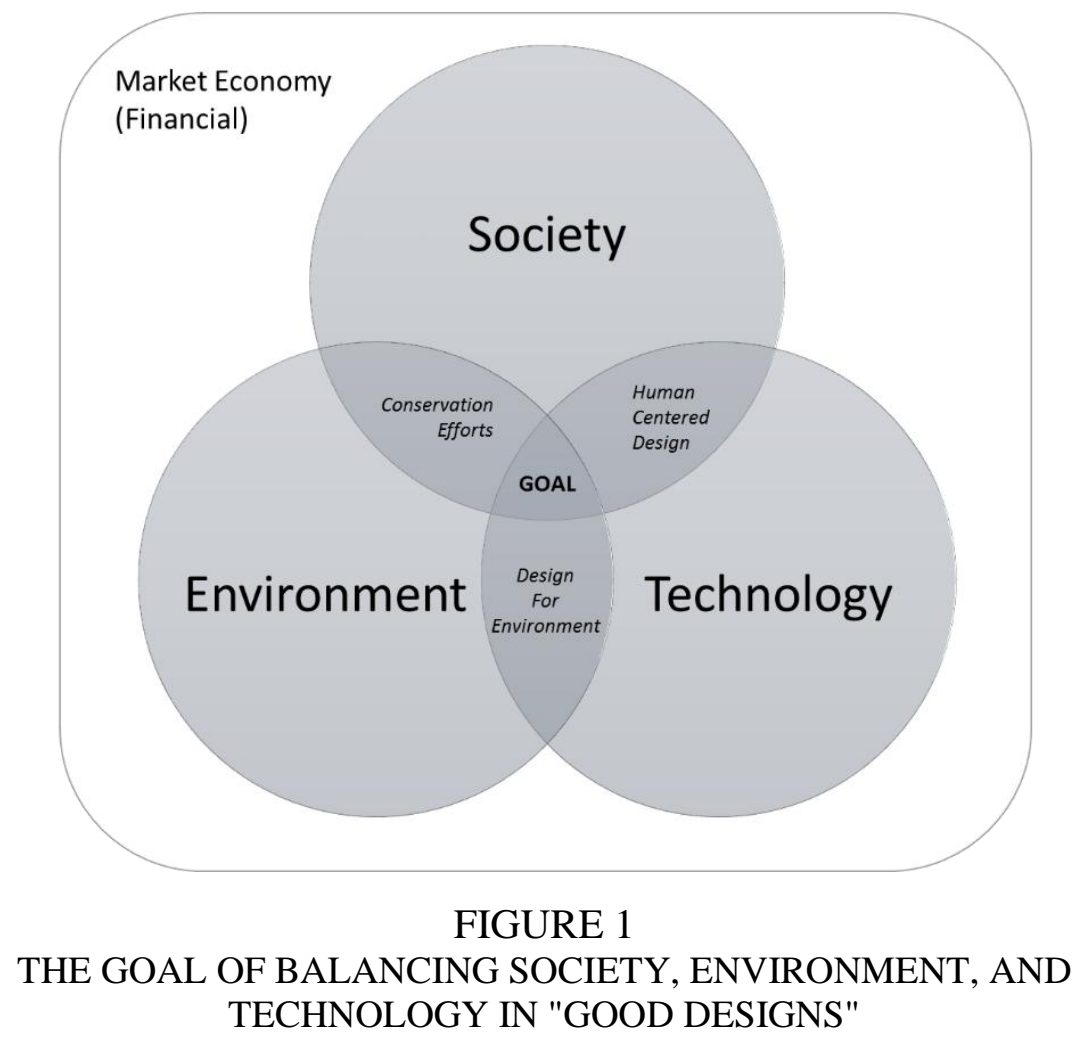

\section{ASSESSMENT FRAMEWORK}

Defining "Good Design" is an important step, but will not stick with students unless the assessment criteria of the class are aligned. In Projects for People the definition is explicitly referenced in the major written and oral course deliverables. Half of the possible points available (500 points out of 1000 total) in the course explicitly reference the definition. An additional 50 points are assigned to an individual lessons learned assignment which asks the students to reflect on their work throughout the course of the semester in light of the design definition. TABLE 1 shows the grade breakdown for the course. 


\begin{tabular}{lcll} 
& \multicolumn{3}{c}{ TABLE 1 } \\
$\begin{array}{lcl}\text { PROJECTS FOR PEOPLE GRADE STRUCTURE BREAKDOW } \\
\text { Group Assignments }\end{array}$ & 75 & Resubmission encouraged, det \\
Social Deliverable & 75 & Resubmission encouraged, det \\
Technical Deliverable & 75 & Resubmission encouraged, det \\
Financial Deliverable & 75 & Resubmission encouraged, det \\
Sustainability Deliverable & 200 & (3 reviews, 50pts for review 1, 75 \\
Phase gate Reviews & 100 & \\
Final Report & $\mathbf{6 0 0}$ & \\
\multicolumn{1}{c}{ Total Group Points } & & \\
Individual Assignments & 100 & \\
Proto 1 Challenge & 100 & \\
Research Review Assignment & 75 & (3 surveys, equally weighted) \\
CATME (Peer Assessment) & 50 & \\
Individual Lessons Learned & 75 & \\
Class Participation & $\mathbf{4 0 0}$ & \\
Individual Points & & \\
Total Points & $\mathbf{1 0 0 0}$ &
\end{tabular}

As can be seen in TABLE 2, the four areas of "Good Design" each have their own deliverable required of the team. These deliverables are not pre-defined. Instead, they are developed with the students and partners involved in a project as the semester progresses. Once "good design" is defined, students are encouraged to resubmit the deliverable until they are satisfied with their grade. Some examples of past deliverables are listed below:

TABLE 2

"GOOD DESIGN" DELIVERABLES FOR FALL 2013 AND FALL 2014 CLASSES

\begin{tabular}{|l|l|l|}
\hline Social Deliverable & \multicolumn{1}{|c|}{ Fall 2013 } & \multicolumn{1}{|c|}{ Fall 2014 } \\
\hline Technical Deliverable & $\begin{array}{l}\text { MAThegraphic on Burkina Faso } \\
\text { Temperature in Soils }\end{array}$ & $\begin{array}{l}\text { The Story of Aziz and Aicha - narrative } \\
\text { of the life of the target family }\end{array}$ \\
\hline Financial Deliverable & $\begin{array}{l}\text { Excel Model of Financial } \\
\text { Payback Period of Proposed } \\
\text { Solution }\end{array}$ & $\begin{array}{l}\text { TBD - likely an analysis of additional } \\
\text { income to Aziz and Aicha per unit extra } \\
\text { storage time achieved }\end{array}$ \\
\hline Sustainability Deliverable & $\begin{array}{l}\text { Narrative of proposed solution } \\
\text { as an enabler to future income } \\
\text { growth and opportunities }\end{array}$ & TBD \\
\hline
\end{tabular}


The students are required to complete three phase gate review presentations through the course of the semester. These phase gate review presentations occur at equally spaced, predefined times during the semester (approximately every 4 weeks). Importantly, progress in the reviews is measured against the Phase Gate Definitions (discussed in the next Section PHASE GATES AND SPRINTS) which are explicitly based on the four areas of Good Design.

\section{PROJECT DURATION}

A significant obstacle in previous HE projects undertaken by capstone design teams is project duration. "Poor designs" have been created due to the tyranny of the semester schedule and the standard senior capstone class cycle. In CSM's case, a senior capstone project must be completed in 1.5 semesters. Instead of being beholden to the senior capstone schedule, Projects for People has been designed to accommodate projects that can span from less than a semester to multi-year commitments. FIGURE 2 graphically shows how Projects for People can accommodate a variety of project lengths while the senior capstone sequence is unable to go beyond a contrived schedule.

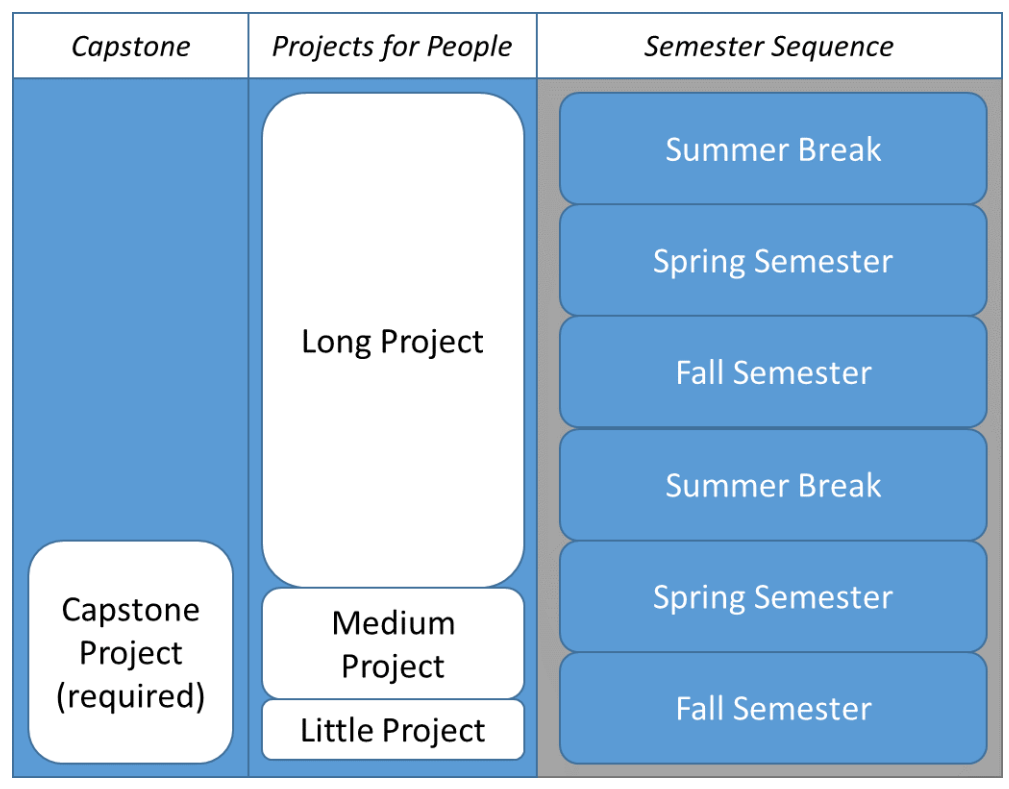

FIGURE 2

BREAKING AWAY FROM THE TyRANNY OF THE SENIOR CAPSTONE PROJECT SCHEDULE

Three major mechanisms have been added to the course that drastically improve knowledge transfer from semester to semester. First, students are allowed to take the course more than one time for credit. The course is repeatable for elective credit with a maximum of 6 total hours. Second, the last class period of the semester is used to create a videotaped "lessons learned for the next class" where students talk about their successes, failures, and where they would start if they could do things over next semester. The lessons learned video is not graded. This output is used to kick-start the next team that takes on the challenge and encourages the students to reflect 
on the learning and experience they have had. Finally, as a means to reward each new group to review the previous semester's work, a research review assignment has been added to the course. The research review assignment challenges each student to pick an area of the project and create a seven minute (maximum) presentation on the topic. FIGURE 3 shows how knowledge is transferred from one semester to the next.

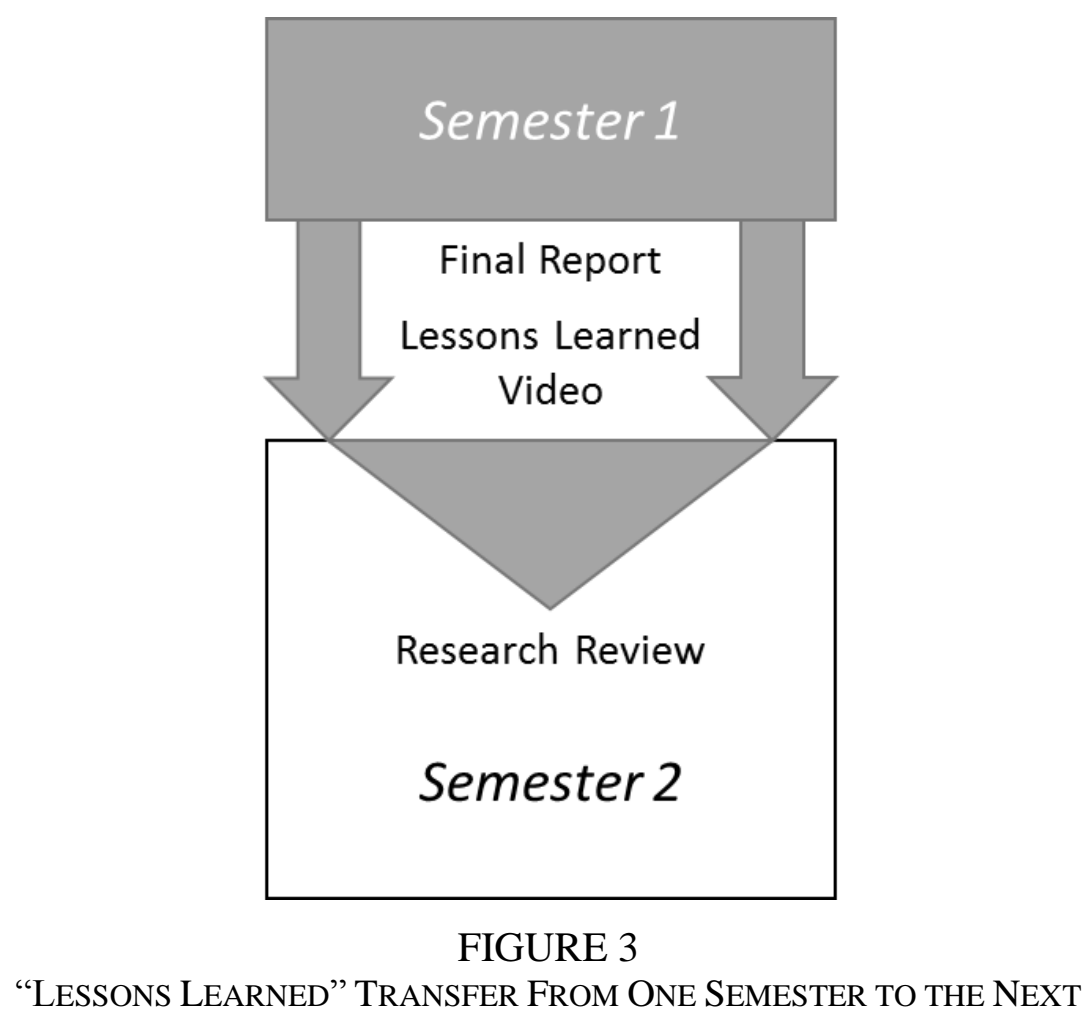

\section{PHASE GATES AND SPRINTS}

In order to implement the previous four methods of addressing the requirements for the course, a phase gate and sprint approach was adopted. Phase gate review processes are commonly used in a variety of industries including product design, software development, and others ${ }^{22,23,24}$. The phase gate process is a technique for project management that forces projects to pass pre-defined quality metrics before proceeding to completion. The general phase gate process currently adopted for the class is shown in FIGURE 4. While the phase-gate process is common in technology development, it is a relatively new design process in engineering for community development ${ }^{25}$. 


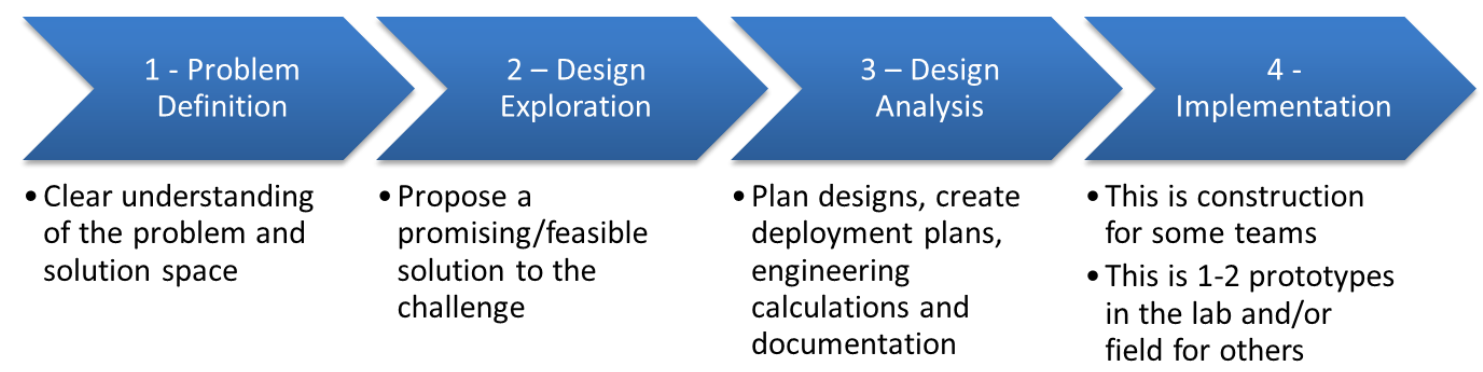

FIGURE 4

Phase Gate Approach Used in the Course

A crucial component of the phase gate approach is having clearly defined goals for student (and instructor) understanding of what project outcomes are acceptable. However, the instructor also needs a mechanism for driving urgency in the students. To that end, Agile Software development has popularized the concept of a design "Sprint"26. A sprint is a defined amount of time before a software team is required to publish the next version of the software. These sprints typically last from 1-6 weeks.

\section{ProjeCts for PeOPLe}

Through implementing the methods discussed in Section 3, the course was developed and the first class of students was instructed in the Fall 2013 semester. Projects for People is now a permanent part of the HE curriculum and is currently being taught in the Fall 2014 semester with plans to teach the course once per term, and with multiple sections as warranted by student enrolment, for the foreseeable future.

Projects for People is a project-based course intended to allow students experience in iterative problem solving. Hands-on testing and prototyping are encouraged throughout the course. The first two weeks of the course are traditional lecture. These introductory lectures introduce human centered design, the definition of good design previously discussed, and class logistics. After the first two weeks, class time is spent as a lab, actively working on a given design challenge. During the majority of the course, instruction is provided just-in-time to address the challenge presented to the class by the NGO partner. Students are split into subgroups for research and development work and work towards three Phase Gate Reviews with the NGO partner.

At the conclusion of the class students will:

1. Apply appropriate technical knowledge to solve a design challenge as demonstrated by peer review and partner review.

2. Demonstrate empathy for the end user/community for which they are designing.

3. Describe the environmental impacts of the technical solution which they are designing.

4. Build low cost, physical prototypes of ideas and concepts.

5. Develop a technical engineering documentation package. 
6. Work in teams over the course of several design sprints.

7. Complete a lessons learned assignment which allows reflection on the social, environmental and technical outcome of the semester.

8. Present work graphically and verbally to industry representatives for critique.

9. Write a final report summarizing the progress made over the course of the semester.

Weaving the concepts from Section 3 together actually creates a very open course structure. This is seen as a strength of the approach. The course schedule for a typical Projects for People semester is outlined in TABLE 3.

TABLE 3

COURSE STRUCTURE

\begin{tabular}{|l|c|l|}
\hline Sprint & Week & Description \\
\hline Course Intro & 1 & Course Introduction \\
\cline { 2 - 3 } & 2 & Human Center Design \\
\hline Sprint 1 & 3 & Sprint Planning and Project Work \\
\cline { 2 - 3 } & 4 & Research Review \\
\cline { 2 - 3 } & 5 & Project Work \\
\cline { 2 - 3 } & 6 & Phase Gate Review \\
\hline Sprint 2 & 7 & Sprint Planning and Project Work \\
\cline { 2 - 3 } & 8 & Project Work \\
\cline { 2 - 3 } & 9 & Project Work \\
\cline { 2 - 3 } & 10 & Phase Gate Review \\
\hline Sprint 3 & 11 & Sprint Planning and Project Work \\
\cline { 2 - 3 } & 12 & Project Work \\
\cline { 2 - 3 } & 13 & Project Work \\
\cline { 2 - 3 } & 14 & Project Work \\
\cline { 2 - 3 } & 15 & Phase Gate Review \\
\hline Wrap Up & 16 & Final Report Completion and Class Lessons Learned \\
\cline { 2 - 3 } & 17 & Individual Lessons Learned \\
\hline
\end{tabular}

The course deliverables and grade weights assigned in the class are detailed in TABLE 1 in the ASSESSMENT FRAMEWORK Section. The majority of the deliverables and grading criteria were also previously discussed. However, three of the assignments listed deserve brief attention.

The Prototyping Challenge is an exciting way to set the tone of the class right from the beginning. The concept was taken from the Extreme Design course at Stanford D.School ${ }^{27}$. Students (in pairs of two) are given one week and \$20 to "solve the problem" of the actual class challenge as their first assignment. The assignment forces the students to quickly communicate any initial ideas or preconceived notions they may have about the design challenge and sets the tone that there will be a bias for action in the class. Student response to the $\$ 20$ challenge has been overwhelmingly positive, with one student stating that it was both the coolest and scariest assignment he had every received in college.

The Research Review assignment is due early on in the first design sprint. The goal of the assignment is to capture and communicate the prior art and background of the project at hand. It 
was added to the course as a way to help students better utilize (1) the work of previous teams and (2) quality information sources after the course faculty realized that students' ability to properly research was limited. The Research Review assignment challenges students to prepare a succinct, 7 minute, presentation of their findings on a given project-relevant topic to the class. Students are encouraged to be creative and avoid PowerPoint if possible. A great presentation will have deep content, clearly presented. Conclusions and actionable data should be discussed with references made to appropriate supporting information.

The final assignment for the class is a chance for the students to reflect on their personal experience and growth through the semester. The Individual Lessons Learned assignment is an essay prompt based on lessons learned practices used in the Purdue EPICS ${ }^{28}$. Students are asked to critically reflect on at least two of four areas. These areas include personal and professional development, social impact, academic enhancement, and engineering by doing.

\section{Project Example}

Two project prompts have been undertaken by this course to date. The project prompts have been explicitly chosen to be items that require a level of understanding and timescale that is not achievable in our capstone program.

The first, exploring post-harvest crop storage solutions for small-holder farmers with iDE (a Denver-based NGO), has been used for two consecutive terms and is primarily a product development challenge. The first group of students did not move beyond conceptual design before running into problems with their proposed solution. The second team, currently working this semester, has taken the work of the previous team and is building upon their successes and failures to move the project forward.

The second project, a Corporate Social Responsibility (CSR) challenge, is in partnership with several extractive industry representatives to explore what responsible community relocation due to a new mining operation would look like. The challenge is primarily an infrastructure and construction design challenge. This is the first semester for the class to include a CSR challenge. However, preliminary student and partner feedback is extremely positive.

\section{OUTCOMES TO DATE}

A number of faculty are involved in teaching and developing the course from a number of departments and backgrounds including the Mechanical Engineering Department (Jered Dean design), the Liberal Arts and International Studies Division (Juan Lucena - political, cultural and historical analyses of engineers and engineering), and the Humanitarian Engineering (Mirna Mattjik - agricultural engineering, and Ben Teschner - geological engineering). The course has been team taught by Jered Dean and one of the Humanitarian Engineering staff listed. To date, 20 students have taken the course with a composition primarily of juniors and seniors although some sophomores have been enrolled. In the Spring, the course is hoping to scale up to accept 24 students per section.

The class is accepted as a technical elective in three engineering degree programs and as a general elective in the rest of the degree programs offered at CSM. The course is now a required part of the Humanitarian Engineering Minor curriculum. To date, most students enrolled in the course have found out about the course through word of mouth and advertising posted by the 
Humanitarian Engineering Program. In the future, efforts will be made to make the general CSM student population aware of the course.

The faculty of CSM have generally found the Projects for People course to be useful and rigorous. A significant deliverable is required of the students for each of the four areas (social, technical, financial, sustainable) by the end of the semester. For example, the Fall 2013 project required students to develop thermal model codes in MATLAB to analyze ground temperatures versus depth and soil moisture content. During Fall 2014, students developed a detailed profile of a typical family that would use the product currently being designed as part of their $\mathrm{HE}$ project. The detailed profile gave students a much better understanding of their customers and a picture of the people they are working for. Many of the ideas piloted here, including design sprints, are being considered for implementation in other design courses. The course has been described by faculty as being technical when appropriate, broad-based, and quality of project products is of paramount importance.

The NGOs that the course have partnered with have shown great interest in and appreciation of the structure of the course (phase gates, sprints, multi-semester projects, "good designs"). Rather than receive designs at the end of a semester that may or may not be appropriate for the context, useful, and well-designed, the NGOs now receive good designs when the designs have sufficiently matured. The NGOs have been very appreciative of this approach and its ability to scale to different timelines based upon the complexity of the project and the students' rate of progress. Rather than good designs being the exception, good designs are now the norm and the expectation. Further, focusing on the four deliverables (social, technical, financial, sustainable) has had benefits for the NGOs in the form of good designs that balance the four deliverables rather than ignoring or under-representing one or more of the deliverables in the final design. Currently there is a waiting list of additional NGOs that wish to work with the course.

Feedback from the NGOs include comments such as:

Students [are] much more engaged than [a] typical senior design team. I think this has a lot of reasons [including:?

1) [The course experience is] a more fluid process. Rather than just three meetings [during the course of the term], contact could be made more frequently and test-refine-iterate cycle of development could happen in [the Projects for People class], and each meeting was less of a burden [for the NGO]. In [senior design], the team takes a direction, and they're gone regardless of whether it's the right direction or whether the nature of the project has changed.

2) [The Projects for People course is] less formal. The students in [the course] weren't hung up on formal deliverables as much. Informal prototypes and quick sketching were possible, and were used to help the back-and-forth between [the students and the NGO].

3) [T] he students feel more passionately about [the Projects for People course and topic than they do about senior design projects].

Another notable NGO comment on the Projects for People class and the phase-gate sprint approach is: 
The benefit of working with the [Projects for People] class was definitely the flexibility and that the class deliverables (the [phase] gates) were designed in a way with a pre-set destination in mind. [The course] was setup less [based on] class assignment and more as a real-world problem.

Finally, one NGO participant stated:

CSM should make this course mandatory for undergrads and grads altogether. Many headaches would be saved if more [engineers and scientists] would loosen up their right brain hemisphere!

Students have shown exceptional growth in their understanding of the four deliverables (social, technical, financial, sustainable) during the course. The students went from a poor understanding of the role that the four deliverables play in producing a "good" design to an intimate understanding, as evidenced through student feedback and assignments. One of the biggest achievements that the authors have seen is the shift from students not thinking about the user to the students being very user-focused in their solution process. Student comments such as:

This program has prepared me for life because I actually am [designing for] real life [rather than working on problem sets that were] written down 10 years ago [and] that I'll be quizzed on. This is real stuff, and [this] is something extremely exciting

reinforce the authors' assertions that students are having real, fundamental shifts in their thought processes while learning new engineering techniques and also being fully engaged in interesting real-world projects. Another revealing comment from a student who participated in the Projects for People class is:

... the best part [of the class] is that there is no [pre-determined, closed solution] answer to our challenge. Imagine that! Our class has taken a task or challenge, and even though everything we have done in school has a definite way to do it, or a finite answer, we have no [pre-defined, "correct"] answer. But the craziest part, and I haven't felt like I've done this before, [...] is that we actually devised an answer. We took this big problem, something seemingly impossible, and learned everything we could. Then we managed to narrow down all our knowledge into one solid answer. We actually found something that could work! If this was a test everyone would fail! There is no [one correct] answer! So the fact that now we have to find out if our answer, our solution, is actually possible or even realistic, is completely different from everything else I have ever done in school. I just can't get enough of real engineering by doing, for real people. It's wonderful.

The authors and course faculty have found a significant improvement in the students' ability to work on challenging open-ended projects that require knowledge from multiple domains, multiple previous classes, and material that the students have learned on their own and with their own motivation. For instance, one student noted: 
International Journal for Service Learning in Engineering Special Edition, pp. 222-239, Fall 2014

ISSN 1555-9033

[...] the deliverables are broad and the students are allowed to have input on how to approach the problem[.] I am able to look at the tools that three previous years at [CSM] have given me and choose the ones that will help me find a solution. In most classes, the teachers tell you which approach to use or which program to use to solve a problem, but this class leaves everything open so that I have to decide for myself how to go about it and then ask the instructors for help if I get stuck. Also, the freedom that has been given to us students is similar to what I would expect in the workplace. Though we have deadlines and deliverables, we haven't been given a ton of busy-work or assignments unless they are essential to the success of the project. In industry, I have experienced and will expect this type of approach. The instructors, [the NGO], and the students are all working towards the same goal, which is bigger than any grade. This feeling of trust between the students and the instructors has caused me to work harder than in a lot of other courses because I don't want to let them [or the end users] down, in the same way that I wouldn't want to let my boss or the customers down in life outside of [CSM].

Several students have also reported that they found the ability to fail without significant academic grade consequences empowering and freeing. One student reported:

I love this [class] because we are allowed to fail. In the beginning we were told that we could succeed in helping poor farmers around the world or we could fail. Our grade does not depend on the outcome. We were told that smart people have tried to come up with solutions before, but they have failed. We were told that this was a hard challenge, but that [the NGO] wanted to see if we could solve it. Having the freedom to fail but the challenge to succeed has shifted my thinking and allowed me to focus on the needs of the final consumer [...] rather than the grade I will receive in the class.

The student were very appreciative of being forced to consider the four deliverables (social, technical, financial, sustainable) equally. One student related her first experience with realizing that the project wasn't only focused on technical deliverables:

I want to describe one scenario that has made this class stand out against all of the others I have taken at [CSM]. [A] couple of weeks into the project, the team held a though-gathering session. We [wrote] everything we knew and every question we had about the project on sticky notes, with one idea per note. Then we grouped these into categories [social, technical, financial, sustainable]. The largest category by far was the "technical" category, offering possible solutions and technical barriers to address. Then there were [the] other categories[...] [The] Professor [...] covered up all of the notes in the technical category and told us that we weren't allowed to explore those ideas until we had a grasp on the answers to the questions in the other "soft" categories. This humancentered design approach where the engineering comes second to the understanding of the people was revolutionary to me and has given this project immeasurable depth.

Several hurdles to the continued viability, continued success, and adoption at other universities of the course exist. Currently there exists no textbook for the course. While a set of lectures and supporting material have been developed, the right type of faculty member is needed 
to teach this course. An instructor must possess the following qualities including: (1) strong interest in PBL and acceptance that there are few opportunities to hold traditional lecture, (2) enough time outside of class to work with students and coordinate with NGO partners, and (3) an understanding of $\mathrm{HE}$, and of the challenges of working with $\mathrm{HE}$ projects. Another significant hurdle is funding the projects, as others have found ${ }^{1}$. Many NGOs do not have budget allocations for working with academic programs to develop solutions for the communities the NGOs work with. This is in contrast with senior capstone projects that are not HE-related where significant financial commitment is expected from all participating companies. A final hurdle is convincing some in the wider faculty at CSM that engineering is in fact being taught to students and performed by students. Assessment methods have allayed many concerns but prejudices toward "soft science" still exist.

The HE faculty believe that the biggest contribution of this course to student learning and success is the development of students into "T-shaped people." T-Shaped people are those who have broad knowledge and deep specialization. The goal of developing students into T-shaped people allows students to broaden their experience (horizontal) while applying their technical coursework (vertical). The key to implementing a T-shaped curricular approach was a focus on broadening first, and applying technology second. While there are multiple ways of implementing a T-shaped teaching approach, the faculty chose to build the class around an assessment framework that pushes a broader perspective on HE projects first before technical details are addressed.

\section{CONCLUSION}

The Projects for People course detailed in this article was developed to fill a need in the HE minor curriculum at CSM. The HE minor, originally established in 2004 as the first HE program in the USA, underwent a significant curriculum revision in the 2012/2013 academic year. Several shortcomings in the existing HE curriculum were addressed in the design and implementation of the Projects for People course including: 1) poor designs being created due to the tyranny of the senior capstone design course schedule, 2) students focusing on the technical aspects of a HE project to the detriment of social, financial, and sustainable aspects, 3) loss of knowledge between academic terms due to student turnover. These issues were addressed through several pedagogical methods including 1) implementing a phase gate and sprint approach to project management, 2) development of a robust knowledge transfer system to ensure knowledge is not lost between academic terms, 3) requiring significant work products in social, financial, sustainable, and technical aspects of the design, and 4) allowing projects to span variable timescales based upon the quality of the resulting design and needs of the customer or community.

The course has found enthusiastic acceptance with NGOs. A waiting list has developed of NGOs that wish to work with the Projects for People course. All projects now come from NGOs who act as intermediaries with communities. Students have similarly been enthusiastic about the course with many students reporting the experience has been one of the best and most favorite while at CSM. Learning outcomes have shown that students are learning about the importance of social, financial, sustainable, and technical aspects of HE projects. Faculty outside the HE program at CSM have found the course to be useful, rigorous, and the alumni of the course to be good students. 
Work is ongoing to improve the HE curriculum at CSM. A companion course to Projects for People has been piloted and is under continued development. Additional sections, new NGO partners, new HE projects, and CSR projects are being introduced to the Projects for People course. Methods used in the course are beginning to be implemented into other traditional engineering courses across the CSM campus. The HE faculty expects to continually improve the Projects for People course into the future and build upon the course to develop an integrated multi-year PBL curriculum.

\section{ACKNOWLEDGMENTS}

The authors wish to acknowledge iDE staff and particularly Leslie Light and Sarah Nuernberger for their willingness to donate their time and talents in the development and continued success of this course.

\section{REFERENCES}

[1] K. G. Paterson, A. R. Bielefeldt, C. W. Swan, G. Rulifson, D. Kazmer, and O. Pierrakos, "Designing value into engineering learning through service activities using a blueprint model," International Journal for Service Learning in Engineering, Humanitarian Engineering and Social Entrepreneurship, pp. 64-83, 2014.

[2] E. Von Hippel and M. J. Tyre, "How learning by doing is done: problem identification in novel process equipment," Research Policy, vol. 24, no. 1, pp. 1-12, 1995.

[3] L. E. Carlson and J. F. Sullivan, "Hands-on engineering: learning by doing in the integrated teaching and learning program," International Journal of Engineering Education, vol. 15, no. 1, pp. 20-31, 1999.

[4] W. A. Wulf, "The urgency of engineering education reform," in Proceedings, Conference on Realizing the New Paradigm for Engineering Education, 1998, pp. 28-30.

[5] Two Sides Of The Same Coin: The Employment Crisis And The Education Crisis, March 4, 2014.

[6] D. Jonassen, J. Strobel, and C. B. Lee, "Everyday problem solving in engineering: Lessons for engineering educators," Journal of Engineering Education, vol. 95, no. 2, pp. 139$151,2006$.

[7] E. J. Coyle, L. H. Jamieson, and W. C. Oakes, "Epics: Engineering projects in community service," International Journal of Engineering Education, vol. 21, no. 1, pp. 139$150,2005$.

[8] E. J. Coyle, L. H. Jamieson, and L. S. Sommers, "Epics: A model for integrating servicelearning into the engineering curriculum." Michigan Journal of Community Service Learning, vol. 4, pp. 81-89, 1997. 
[9] J. D. VanderSteen, C. Baillie, and K. Hall, "International humanitarian engineering," Technology and Society Magazine, IEEE, vol. 28, no. 4, pp. 32-41, 2009.

[10] B. Amadei, R. Sandekian, and E. Thomas, "A model for sustainable humanitarian engineering projects," Sustainability, vol. 1, no. 4, pp. 1087-1105, 2009.

[11] J. J. Lucena and J. Dean, "Design with vulnerable communities through ngos: Partnering criteria, relationship building, and design pedagogy," in Tech4Dev Conference, http://cooperation.epfl.ch/2014Tech4Dev/Sessions/6June, 2014, pp. TH2-SE02-13-b.

[12] A. Escobar, Encountering development: The making and unmaking of the Third World. Princeton University Press, 2011.

[13] W. Easterly, The White Man's Burden: Why the West's Efforts to Aid the Rest Have Done So Much Ill and So Little Good. Penguin Group, 2006.

[14] B. G. Tucker, D. O. Kazmer, A. R. Bielefeldt, K. Paterson, O. Pierrakos, A. Soisson, and C. Swan, "Principles of sustaining partnerships between higher education and their larger communities: Perspectives from engineering faculty engaged in learning through service," International Journal for Service Learning in Engineering, Humanitarian Engineering and Social Entrepreneurship, pp. 48-63, 2014.

[15] K. Martens, "Non-governmental organisations as corporatist mediator? an analysis of ngos in the unesco system," Global Society, vol. 15, no. 4, pp. 387-404, 2001.

[16] T. Martindale, "Planning, monitoring, evaluation and learning program program descriptionplanning, monitoring, evaluation and learning program," Engineers Without Borders USA,

https://s3.amazonaws.com/ewbgeneral/COMPILED\%20PMEL\%20Program\%20Description.pdf, Technical Report, 2014.

[17] C. S. of Mines, "Humanitarian engineeering," September 2014. [Online]. Available: http://bulletin.mines.edu/undergraduate/interdisciplinaryminors/humanitarianengineering/

[18] IDEO, "Ideo human-centered design (hed) toolkit (2nd edition)," 2009. [Online]. Available: http://www.ideo.com/images/uploads/hcd_toolkit/IDEO_HCD_ToolKit.pdf

[19] M. Steen, "Tensions in human-centred design," CoDesign, vol. 7, no. 1, pp. 45-60, 2011.

[20] J. J. Lucena, J. Schneider, and J. Leydens, Engineering and Sustainable Community Development, C. Baillie, Ed. San Rafael, CA: Morgan and Claypool, 2010.

[21] NCEES, "Fe reference handbook," National Council of Examiners for Engineering and Surveying, Tech. Rep., 2013.

[22] R. G. Cooper, "Stage-gate systems: a new tool for managing new products," Business horizons, vol. 33, no. 3, pp. 44-54, 1990. 
[23] T. Young, The Handbook of Project Management: A Practical Guide to Effective Policies and Proced. Kogan Page Publishers, 2007.

[24] D. Karlstrom and P. Runeson, "Combining agile methods with stage-gate project management," IEEE software, vol. 22, no. 3, pp. 43-49, 2005.

[25] B. K. Thorn, A. L. Carrano, C. R. Plaz, C. R. Wood, and E. Guedez, "User-driven design framework of low-cost, low environmental impact solar ovens for rural populations in developing countries," Journal of Engineering for Sustainable Community Development, vol. 1, no. 1, pp. 1-12, 2006.

[26] K. Schwaber, "Scrum development process," in Business Object Design and Implementation. Springer, 1997, pp. 117-134.

[27] S. d.School, "Extreme by design." [Online]. Available: http://www.extremebydesignmovie.com/

[28] S. L. Ash, P. H. Clayton, and M. G. Moses, "Learning Through Critical Reflection: A Tutorial for Service-Learning Students," PHC Ventures, 2009. 